\title{
Respiratory illness in British schoolchildren and atmospheric smoke and sulphur dioxide 1973-7 \\ I: Cross-sectional findings
}

\author{
R. J. W. MELIA, C. du V. FLOREY, AND A. V. SWAN \\ From the Department of Community Medicine, St. Thomas's Hospital Medical School, London
}

SUMMARY The relation between respiratory illness and atmospheric smoke and sulphur dioxide $\left(\mathrm{SO}_{2}\right)$ was investigated from 1973 to 1977 in children aged 6 to 11 from a random sample of 28 areas in England and Scotland. Cross-sectional results are presented for 1975, and results from other years briefly summarised. In 1975 there were 19 areas with data on pollution and in these areas the sample included 5787 children of white ethnic origin of whom $4116(71 \%)$ had complete information on respiratory illness and other variables considered in the analysis.

After allowing for the effects of age, social class, population density, type of fuel used for cooking in the home, and season of examination, the prevalence of respiratory illness in both sexes was positively associated with the levels of smoke over the range of annual means 8 to $51 \mu \mathrm{g} / \mathrm{m}^{3}$ $(p \leqslant 0 \cdot 05)$. No relation was found between illness and annual means of $\mathrm{SO}_{2}$ ranging from 12 to 114 $\mu \mathrm{g} / \mathrm{m}^{3}$. Similar results were found in other years, and in 1977 , when information on tobacco smoking at home was collected, the association between illness and atmospheric smoke appeared to be independent of smoking within the home.

The levels of smoke were much lower than those at which effects on health have previously been reported so the association is unlikely to be causative. We postulate that higher levels of atmospheric pollution at an earlier period in some areas may have predisposed children living there to respiratory illness during their primary school years. Alternatively, some other characteristics of the polluted areas may explain the findings.

The levels of atmospheric smoke and sulphur dioxide $\left(\mathrm{SO}_{2}\right)$ have been declining over several decades in the United Kingdom ${ }^{1}$ and during the 1960s it appeared that the effects of pollution on respiratory illness in children might be disappearing. ${ }^{2}$ While the levels of pollution declined further in later years, a study was conducted to investigate the effect on health from low levels of pollution.

A national sample of primary schoolchildren from England and Scotland was examined from 1973 to 1977. Children aged 6 to 11 were studied because they have previously been shown to be susceptible to the effects of smoke and $\mathrm{SO}_{2}$ and their history of exposure to pollution is likely to be less varied than that of adults. Very few children of these ages smoke tobacco or are exposed to occupational pollutants and they have had less time in which to move home than adults.
The study had two main aims: firstly, to examine cross-sectionally the relation between the prevalence of respiratory illness and annual levels of pollution in the study areas, and secondly, to examine over time the relation between changes in health and changes in levels of pollution within areas. The results of cross-sectional analyses are presented here for 1975 and those from other years are briefly summarised. The results of longitudinal analyses are given in the accompanying paper. ${ }^{4}$

\section{Methods}

POPULATION AND DATA COLLECTION

The study was conducted in conjunction with a national study of health and growth which had been set up in 1972. Children were studied from selected schools in 22 English and six Scottish areas which had 
been selected by stratified random sampling from a total of 597 employment exchange areas so that poorer areas had proportionately greater representation. Details of the method of sampling have been given by Altman and Cook. ${ }^{5}$ In 1977 the selected schools in four areas were unable to take part and other state schools were substituted within the areas. A further four areas refused to continue in the study and near-by areas with the same socioeconomic index were randomly selected as replacements. One of the new areas was not ready to participate in 1977. The age range was extended in 1977 to include 5-year-olds.

The study was of a mixed longitudinal design: each year new children entered the study when they began at primary school and older children left when they moved on to secondary school. Those aged 6 to 11 who moved into the area were included in the sample but those who left were not followed up. Thus the period for which children remained in the study varied from one to five years.

Trained fieldworkers from our department organised the fieldwork in 18 English areas during the summer school term and in the remaining areas during the autumn. A self-administered questionnaire was completed annually by each child's mother or other guardian. There were six questions on respiratory conditions. The mother was asked whether her child usually experienced morning cough, day or night cough, or colds going to the chest, whether her child's chest ever sounded wheezy or whistling, and the number of attacks from asthma and bronchitis experienced during the past 12 months. Data were also obtained on socioeconomic characteristics of the home, such as the father's occupation, the type of fuels used for cooking and heating in the home and, in 1977 only, the number of people in the home who regularly smoked cigarettes, cigars, and pipes. The father's occupation was classified into one of six social class groups defined by the Registrar General ${ }^{6}$ and these were aggregated into three broad groups I-IIIa (non-manual), IIIb (skilled manual) and IV and V (semi-skilled or unskilled) as there were few children in classes I and V.

Smoke and $\mathrm{SO}_{2}$ were sampled every 24 hours by the British Standard Smoke/ $/ \mathrm{SO}_{2}$ method $^{7}$ at or near the children's schools in each area. Most children lived within half a mile of their schools so the monitoring sites were considered to provide measurements representative of the area in which the children both lived and attended school. ${ }^{\mathrm{s}}$ Information on population density was obtained from the 1971 census for the boroughs in the selected areas.

MEASURES OF RESPIRATORY ILLNESS

Some interrelationship was found between the responses to the six respiratory questions but the responses did not fall into any obvious subgroups. Therefore we decided simply to count the number of conditions reported for each child in response to the six respiratory questions in the questionnaire to obtain an overall measure of respiratory illness as in previous analyses from the study. ${ }^{910}$ The children were grouped into those who had one condition or more present and those who had three conditions or more in response to the six respiratory questions.

MEASURES OF POLLUTION

The daily measurements of pollution in each area were studied over the 12 months preceding the fieldworker's visit to each area. The mean levels during the winter quarter were used because these provided a wider separation between areas with low and high levels of pollution than did measurements from other seasons. Annual means could be calculated for fewer areas than winter means but they were of special interest because they have been used to set air quality standards. ${ }^{11}{ }^{12}$ In initial analyses the areas were divided into groups according to whether they had less than $30 \mu \mathrm{g} / \mathrm{m}^{3}$, from 30 to $60 \mu \mathrm{g} / \mathrm{m}^{3}$, or over 60 $\mu \mathrm{g} / \mathrm{m}^{3}$ mean winter levels of smoke or $\mathrm{SO}_{2}$. The cutting points were chosen so that the number of areas in each group was similar. In subsequent analyses the individual levels of pollution in each area were used.

\section{STATISTICAL METHODS}

In simple tabulations the $\chi^{2}$ test for trend was used to study the relation between the prevalence rates and individual variables. To allow for the effects of interfering variables a regression analysis was conducted which uses a binary response in the dependent variable such as presence or absence of illness. This was done by assuming that the 'true' prevalences could be represented by a linear combination of factor and covariate effects on the logistic scale according to the principles discussed by Dyke and Patterson. ${ }^{13}$ The computer package GENSTAT $^{14}$ was used to perform most analyses.

\section{Results}

\section{RESPONSE RATES}

The main analysis presented here is for children studied in 1975. Of 15004 children who had entered the study by then, $8001(53 \cdot 3 \%)$ were followed up in 1975. The majority of the 7003 who were not followed up had left the study because they had moved on to secondary school. Of the 8001 children, $6093(76.2 \%)$ came from the 19 areas with data on winter mean levels of pollution. One hundred and seventy-three children were excluded because their 
ethnic group was either non-white or unknown and 133 were omitted because their age was outside the range 6 to 11 . Of the 5787 aged 6 to 11 of white ethnic origin, $1575(27 \cdot 2 \%)$ were excluded from analysis because they had information missing on the six respiratory questions or on father's social class. We also excluded 96 children where some fuel other than gas only or electricity only was used for cooking. In conclusion, $4116(71 \cdot 1 \%)$ of the 5787 children in the 19 areas were available for analysis. This response rate did not differ appreciably from that in the remaining nine areas which did not have full information on pollution levels (73.4\%) and the children from the two sets of areas did not differ significantly in height or weight within age and sex groups.

\section{LEVELS OF POLLUTION}

We first examined the range of levels of pollution in the 19 study areas in 1975 and the relation between various measures of pollution. 1974-5 winter mean levels of smoke ranged from 11.9 to $72.5 \mu \mathrm{g} / \mathrm{m}^{3}$ and those of $\mathrm{SO}_{2}$ from 18.5 to $145.4 \mu \mathrm{g} / \mathrm{m}^{3}$. The levels of the two pollutants were positively correlated with one another $(r=0.66, p<0.01)$. Annual means could be calculated only for 16 areas in 1975 . These ranged from 8.2 to $50.5 \mu \mathrm{g} / \mathrm{m}^{3}$ for smoke and from 12.0 to $114 \cdot 1 \mu \mathrm{g} / \mathrm{m}^{3}$ for $\mathrm{SO}_{2}$. The winter and annual means of each pollutant were positively correlated with one another (for smoke: $r=0.97, p<0.001$; for $\left.\mathrm{SO}_{2} \mathrm{r}=0.88, \mathrm{p}<0.001\right)$.

\section{UNADJUSTED PREVALENCE RATES}

In boys (Table 1) there appeared to be heterogeneity in the prevalence of one or more respiratory conditions among the three groups of areas with low, medium, or high levels of smoke $(p<0.05)$ but no statistically significant trend in prevalence rate was found across the three groups $(p>0 \cdot 10)$. The prevalence rate in boys of three or more respiratory conditions (Table 1) did not differ between the areas grouped by their levels of smoke $(p>0 \cdot 10)$ or show a significant trend across the groups $(p>0.10)$ although the rate did appear to be lowest in the low polluted areas and highest in the high polluted areas. Although the trend was not significant there was a slight suggestion of curvilinear relationship but investigation of this was left to the regression analyses.

In girls, both the prevalence rate of one or more and three or more respiratory conditions showed heterogeneity among the three groups of areas with low, medium, or high levels of smoke $(p<0.05)$ and a trend in prevalence rate was found across the groups, the rate being highest in the most polluted areas $(p<0 \cdot 05)$.

Similar results were observed for both sexes when the areas were grouped by their winter levels of $\mathrm{SO}_{2}$ (Table 2).

INTERFERING VARIABLES

The prevalence rate in both sexes of one or more respiratory conditions tended to be higher in younger

Table 1 Unadjusted prevalence rates (\%) ofone or more and three or more respiratory conditions in boys and girls by winter mean levels of smoke in 1975

\begin{tabular}{|c|c|c|c|c|c|c|c|c|c|c|}
\hline \multirow{3}{*}{$\begin{array}{l}\text { No. of } \\
\text { respiratory } \\
\text { conditions }\end{array}$} & \multicolumn{5}{|c|}{ BOYS } & \multicolumn{5}{|c|}{ GIRLS } \\
\hline & \multicolumn{3}{|c|}{ Level of smoke $\left(\mu g / m^{3}\right)$} & \multirow{2}{*}{\multicolumn{2}{|c|}{$\begin{array}{l}\text { Significance for } \\
\chi_{2}^{2} \quad \chi_{1}^{2} \text { for trend }\end{array}$}} & \multicolumn{3}{|c|}{ Level of smoke $\left(\mu g / m^{2}\right)$} & \multirow{2}{*}{$\begin{array}{l}\text { Significance } \\
\chi_{2}^{2}\end{array}$} & \multirow{2}{*}{$\chi_{1}^{2}$ for trend } \\
\hline & $<30$ & $30-60$ & $>60$ & & & $<30$ & $30-60$ & $>60$ & & \\
\hline $\begin{array}{l}1 \text { or more } \\
3 \text { or more }\end{array}$ & $\begin{array}{r}28 \cdot 8 \\
5 \cdot 4\end{array}$ & $\begin{array}{r}23 \cdot 6 \\
5 \cdot 7\end{array}$ & $\begin{array}{r}31 \cdot 2 \\
8 \cdot 0\end{array}$ & $\begin{array}{l}p<0.05 \\
p>0.10\end{array}$ & $\begin{array}{l}p>0.10 \\
p>0.10\end{array}$ & $\begin{array}{r}22 \cdot 9 \\
3 \cdot 3\end{array}$ & $\begin{array}{r}20 \cdot 4 \\
4 \cdot 6\end{array}$ & $\begin{array}{r}30 \cdot 3 \\
7 \cdot 7\end{array}$ & $\begin{array}{l}p<0.05 \\
p<0.05\end{array}$ & $\begin{array}{l}p<0.05 \\
p<0.005\end{array}$ \\
\hline $\begin{array}{l}\text { Total no. } \\
\text { of children }\end{array}$ & 962 & 794 & 311 & & & 910 & 789 & 350 & & \\
\hline
\end{tabular}

Table 2 Unadjusted prevalence rates (\%) ofone or more and three or more respiratory conditions in boys and girls by winter mean levels of $\mathrm{SO}_{2}$ in 1975

\begin{tabular}{|c|c|c|c|c|c|c|c|c|c|c|}
\hline \multirow{3}{*}{$\begin{array}{l}\text { No. of } \\
\text { respiratory } \\
\text { conditions }\end{array}$} & \multicolumn{5}{|c|}{ BOYS } & \multicolumn{5}{|c|}{ GIRLS } \\
\hline & \multicolumn{3}{|c|}{ Level of $\mathrm{SO}_{2}\left(\mu \mathrm{g} / \mathrm{m}^{3}\right)$} & \multirow{2}{*}{\multicolumn{2}{|c|}{$\begin{array}{l}\text { Significance for } \\
\chi_{2}^{2} \quad \chi_{1}^{2} \text { for trend }\end{array}$}} & \multicolumn{3}{|c|}{ Level of $\mathrm{SO}_{2}\left(\mu \mathrm{g} / \mathrm{m}^{3}\right)$} & \multirow{2}{*}{\multicolumn{2}{|c|}{$\begin{array}{l}\text { Significance for } \\
\chi_{2}^{2} \quad \chi_{1}^{2} \text { for trend }\end{array}$}} \\
\hline & $<30$ & $30-60$ & $>60$ & & & $<30$ & $30-60$ & $>60$ & & \\
\hline $\begin{array}{l}1 \text { or more } \\
3 \text { or more }\end{array}$ & $\begin{array}{r}23 \cdot 5 \\
5 \cdot 1\end{array}$ & $\begin{array}{r}30 \cdot 2 \\
6 \cdot 2\end{array}$ & $\begin{array}{r}29.8 \\
6.9\end{array}$ & $\begin{array}{l}p<0.05 \\
p>0.10\end{array}$ & $\begin{array}{l}p>0 \cdot 10 \\
p>0 \cdot 10\end{array}$ & $\begin{array}{r}21 \cdot 3 \\
3 \cdot 3\end{array}$ & $\begin{array}{r}21 \cdot 1 \\
3 \cdot 3\end{array}$ & $\begin{array}{r}27 \cdot 9 \\
7 \cdot 5\end{array}$ & $\begin{array}{l}\mathrm{p}<0.05 \\
\mathrm{p}<0.05\end{array}$ & $\begin{array}{l}\mathrm{p}<0.01 \\
\mathrm{p}<0.05\end{array}$ \\
\hline $\begin{array}{l}\text { Total no. } \\
\text { of children }\end{array}$ & 919 & 615 & 533 & & & 872 & 579 & 598 & & \\
\hline
\end{tabular}


Table 3 Unadjusted prevalence rate (\%) of one or more respiratory conditions by age and social class

\begin{tabular}{|c|c|c|c|c|c|c|c|c|}
\hline \multirow[b]{2}{*}{ Age (years) } & \multicolumn{4}{|l|}{ BOYS } & \multicolumn{4}{|l|}{ GIRLS } \\
\hline & $<8$ & 8-9 & $>9$ & $\begin{array}{l}\text { Significance for } \\
\chi_{1}^{2} \text { for trend }\end{array}$ & $<8$ & $8-9$ & $>9$ & $\begin{array}{l}\text { Significance for } \\
\chi_{1}^{2} \text { for trend }\end{array}$ \\
\hline Prevalence rate (\%) & $30 \cdot 2$ & 26.9 & $26 \cdot 1$ & $p>0.15$ & 27.6 & $22 \cdot 7$ & $18 \cdot 8$ & $p<0.001$ \\
\hline Total no. of children & 693 & 760 & 614 & & 681 & 776 & 592 & \\
\hline Social Class & I-IIIa & IIIb & IV-V & $\begin{array}{l}\text { Significance for } \\
\chi_{1}^{2} \text { for trend }\end{array}$ & I-IIIa & IIIb & IV-V & $\begin{array}{l}\text { Significance for } \\
\chi_{1}^{2} \text { for trend }\end{array}$ \\
\hline Prevalence rate (\%) & $24 \cdot 5$ & $28 \cdot 4$ & 27.9 & $p>0.15$ & $18 \cdot 6$ & $24 \cdot 9$ & $25 \cdot 4$ & $p<0.01$ \\
\hline Total no. of children & 597 & 1065 & 405 & & 586 & 1026 & 437 & \\
\hline
\end{tabular}

than older children and higher in Social Classes IIIb to $\mathrm{V}$ than in classes I to IIIa (Table 3). Statistically significant associations were found in girls but not boys. The prevalence rate of three or more respiratory conditions showed similar associations to age and social class. Small differences in age were found between the areas which might have interfered with the relations between respiratory illness and pollution observed in Tables 1 and 2, and social class may well have affected the results because a higher proportion of children from Social Classes IIIb to $\mathrm{V}$ came from the high than from the low polluted areas. The association between social class and levels of $\mathrm{SO}_{2}$ is illustrated in Table 4.

Several other variables were considered in the analyses because there was a possibility that they were associated with both respiratory illness and pollution. The type of fuel used for cooking in the home was studied because in $1973^{\circ}$ and $1977^{10}$ the prevalence of respiratory illness was found to be higher in homes where gas was used for cooking than in homes where electricity was used. Population density was taken into account because the levels of pollution tended to be higher in urban areas where there was also expected to be more overcrowding and poorer social conditions than in rural areas. Lastly, we decided to include the season when the children were examined in each area. All Scottish areas were studied in the autumn, whereas most areas from northern England were visited in the summer, so regional characteristics may have caused differences

Table 4 Percentage of children by father's social class in areas with low and high winter mean levels of $\mathrm{SO}_{2}$

\begin{tabular}{lcc}
\hline & \multicolumn{2}{c}{ Winter mean level of $\mathrm{SO}_{2}\left(\mathrm{\mu g}_{\mathrm{g}} \mathrm{m}^{2}\right)$} \\
\cline { 2 - 3 } Social Class & $18-49$ & $50-145$ \\
\hline I-IIIa & $31 \cdot 3$ & 23.4 \\
IIIb & $50 \cdot 1$ & $52 \cdot 2$ \\
IV-V & 18.6 & 24.4 \\
Total* & $100 \cdot 0$ & 100.0 \\
& $(2794)$ & $(1322)$ \\
\hline
\end{tabular}

*No. of children in brackets in the reporting of respiratory illness between the two seasons. It was also possible that recall of respiratory illness may have been less accurate for mothers reporting in the autumn than in the summer because more time would have elapsed from the previous winter when most illness was expected to occur.

PREVALENCE RATES, POLLUTION AND INTERFERING VARIABLES

Regression analyses were conducted to study the relation between the prevalence rates, continuous measures of pollution, and interfering variables. Analyses were conducted separately for boys and girls because there was not enough space in the computer memory to analyse the full regression model for the sexes together.

To investigate the possibility of a non-linear relation between respiratory illness and pollution we included a quadratic (squared) term for both smoke and $\mathrm{SO}_{2}$ in the regression model. Comparisons of this model with the linear model omitting the quadratic term allowed us to assess curvilinear relations between respiratory illness and pollution. There was no evidence in either sex of curvature in the relation between respiratory illness and $\mathrm{SO}_{2}$. However a curved relation was just significantly better than a linear relation for smoke in girls from areas visited in the summer. The interpretation of this finding is unclear because over the range of smoke levels 12 to $73 \mu \mathrm{g} / \mathrm{m}^{3}$ the prevalence of respiratory illness appeared to start high, fall, and then rise again. As this trend was only just significant in one subset of children and showed an unusual pattern, we decided to proceed with the linear model to summarise trends in the relation between respiratory illness and smoke.

In both sexes the prevalence rate of one or more respiratory conditions was significantly higher in younger than older children and higher in Social Classes IIIb and IV to V than in classes I to IIIa (Table 5). None of the other variables appeared to be related to the prevalence rate in boys but in girls a relation between the prevalence of one or more respiratory conditions and winter levels of smoke was 
Table 5 Results of regression analysis showing relation of logit of rate of one or more respiratory conditions in boys and girls to winter mean levels of smoke and $\mathrm{SO}_{2}$ and confounding variables

\begin{tabular}{|c|c|c|}
\hline \multirow[b]{2}{*}{ Regression model } & \multicolumn{2}{|c|}{ REGRESSION EQUATION } \\
\hline & Boys & Girls \\
\hline Constant & -0.143 & -0.078 \\
\hline Age & $-0.041^{* *}$ & $-0.070^{* * *}$ \\
\hline $\begin{array}{l}\text { Social Class } \\
\text { IIIb } \\
\text { IV, V }\end{array}$ & $\begin{array}{l}0.117^{*} \\
0.097\end{array}$ & $\begin{array}{l}0.198^{* *} \\
0 \cdot 193^{* *}\end{array}$ \\
\hline $\begin{array}{l}\text { Cooking fuel } \\
\text { Gas }\end{array}$ & 0.019 & -0.014 \\
\hline Population density & -0.004 & 0.001 \\
\hline $\begin{array}{l}\text { Season of examination } \\
\text { Autumn }\end{array}$ & -0.027 & -0.061 \\
\hline $\begin{array}{l}\text { Season X smoke } \\
\text { Summer: smoke } \\
\text { Autumn: smoke }\end{array}$ & $\begin{array}{r}0.002 \\
-0.003\end{array}$ & $\begin{array}{c}0.004^{*} \\
-0.004\end{array}$ \\
\hline $\begin{array}{l}\text { Season } \mathrm{X} \mathrm{\textrm {SO } _ { 2 }} \\
\text { Summer: } \mathrm{SO}_{2} \\
\text { Autumn: } \mathrm{SO}_{2}\end{array}$ & $\begin{array}{l}0.0004 \\
0.002\end{array}$ & $\begin{array}{r}-0.001 \\
0.002\end{array}$ \\
\hline
\end{tabular}

found which depended on season of examination. In areas visited in the summer the prevalence rate was higher in areas with high levels of smoke than in areas with low levels $(p \bumpeq 0.05)$. This was not found in areas visited in the autumn. In neither sex did the prevalence of one or more respiratory conditions appear to be related to levels of $\mathrm{SO}_{2}$.

The prevalence rate of three or more respiratory conditions in boys and girls was associated with few variables in the analysis (Table 6) but the rate did tend to be higher in younger than older children and higher in girls from Social Classes IIIb and IV to V than in those from classes I to IIIa, as had been found for the prevalence of one or more respiratory conditions. In areas visited in the summer, a positive association was found between the prevalence of three or more respiratory conditions and winter levels of smoke in boys $(\mathrm{p}<0.05)$ but not girls. In neither sex were the levels of $\mathrm{SO}_{2}$ related to the prevalence rate of three or more respiratory conditions.

\section{ADDITIONAL ANALYSES}

It was possible that some characteristics of the children's homes or study areas other than those considered above may have biased the results towards finding an association between respiratory illness and levels of smoke. Consequently the analysis was extended to include an assessment of effects on health from overcrowding, type of heating fuels in the home, weather conditions, and the proportion of
Table 6 Results of regression analysis showing relation of logit of rate of three or more respiratory conditions in boys and girls to winter mean levels of smoke and $\mathrm{SO}_{2}$ and confounding variables

\begin{tabular}{|c|c|c|}
\hline \multirow[b]{2}{*}{ Regression model } & \multicolumn{2}{|c|}{ REGRESSION EQUATION } \\
\hline & Boys & Girls \\
\hline Constant & -0.797 & $-1.863^{* *}$ \\
\hline Age & -0.048 & -0.032 \\
\hline $\begin{array}{l}\text { Social Class } \\
\text { IIIb } \\
\text { IV, V }\end{array}$ & $\begin{array}{r}-0.024 \\
0.026\end{array}$ & $\begin{array}{l}0.007 \\
0.282\end{array}$ \\
\hline $\begin{array}{l}\text { Cooking fuel } \\
\text { Gas }\end{array}$ & -0.043 & 0.113 \\
\hline Population density & 0.0007 & 0.002 \\
\hline $\begin{array}{l}\text { Season of examination } \\
\text { Autumn }\end{array}$ & -0.135 & 0.029 \\
\hline $\begin{array}{l}\text { Season X smoke } \\
\text { Summer: smoke } \\
\text { Autumn: smoke }\end{array}$ & $\begin{array}{l}0.008^{*} \\
0.004\end{array}$ & $\begin{array}{l}0.005 \\
0.012\end{array}$ \\
\hline $\begin{array}{l}\text { Season X } \mathrm{SO}_{2} \\
\text { Summer: } \mathrm{SO}_{2} \\
\text { Autumn: } \mathrm{SO}_{2}\end{array}$ & $\begin{array}{l}-0.004 \\
-0.003\end{array}$ & $\begin{array}{r}0.004 \\
-0.002\end{array}$ \\
\hline
\end{tabular}

children in each area with one or more smokers in the home estimated from data collected in 1977. However, as this information was missing for about $20 \%$ of the 4116 children in the main analysis, and weather was not recorded at stations within the study areas, the results should be treated with some caution. The size of the associations between respiratory illness and smoke pollution measured by the regression coefficients was the same in the additional analyses as before but the associations were no longer statistically significant. Therefore, within the limits of the additional analyses, the associations with pollution did not seem to be disguised effects of these additional variables and the loss of significance may have been due to the data being spread over a large number of subgroups.

In further analyses of data from 1975 the prevalence of respiratory illness was found to be associated with annual mean levels of pollution in a similar manner to winter mean levels. Thus the prevalence rates of one or more respiratory conditions in girls and of three or more conditions in boys were positively associated with annual levels of smoke but not $\mathrm{SO}_{2}$.

Similar results were found in other years of the study. In 1977, when data on smoking in the home were collected for each child, the presence of one or more smokers in the home showed no consistent relation to the prevalence of respiratory illness in either sex and did not affect the relation between respiratory illness and levels of atmospheric smoke. 


\section{Discussion}

The association between respiratory illness and levels of smoke found in 1975 confirms the results from a preliminary analysis of data collected in 1973 when levels of pollution from only one month were used to estimate the type of exposure which children were receiving in 10 areas. $^{15}$ In another preliminary report $^{16}$ on cross-sectional results from 1975 an association between respiratory illness and smoke was discounted because it had been found only in girls, but the prevalence of three or more respiratory conditions had not been investigated at that stage.

Apart from smoke, only age and social class showed marked significant associations with the prevalence of respiratory illness. No association was found between respiratory illness and gas cooking, unlike the findings in other years, ${ }^{910}$ but it had not been possible with restricted space in the computer program to study this association in greater detail. In previous analyses the association was most consistent in urban areas only.

The results seem to support an association between respiratory illness and levels of smoke despite certain inconsistencies. The association was found only in areas visited in the summer but these areas had higher levels of pollution than areas visited in the autumn. Although the association between respiratory illness and levels of smoke might appear to be inconsistent between the sexes, the size of the association measured by the regression coefficients did not differ significantly between the sexes. The strength of the association appeared to be greater for the prevalence of three or more respiratory conditions than for the prevalence of one or more conditions, particularly in boys. However, this might be expected if the presence of three or more conditions provided a measure of severe illness and children with severe illness were more sensitive to the effects of pollution.

However, the interpretation of the association is not necessarily one of cause and effect. Pollution may be acting as a proxy or in combination with other characteristics of the areas such as those arising between regions, particularly as the most polluted areas were in the north and the least polluted areas in the south of England. It had not been possible to include location of the areas by region in the analysis because the sample size was not large enough to be spread over these extra groups. Furthermore the prevalence rates may be determined in part by sequelae of illness ${ }^{17}{ }^{18}$ so differences in past as well as present environment may have caused differences in health between areas.

If some portion of the children's respiratory illness was due to contemporaneous pollution it was at much lower levels than would have been expected from the results of previous studies. In primary schoolchildren from Sheffield, England, the prevalence rates of respiratory conditions were compared between areas of the city with different levels of atmospheric pollution. ${ }^{2}{ }^{3}$ The prevalence rates in 5-year-olds were significantly higher in areas with high levels of pollution than in areas with low levels over the range of annual means 97 to $301 \mu \mathrm{g} / \mathrm{m}^{3}$ for smoke and 123 to $275 \mu \mathrm{g} / \mathrm{m}^{3} \mathrm{SO}_{2}$. However, when the children were re-examined four years later, the difference in prevalence rates between the areas was no longer significant, possibly because the annual means of the clean area and the three polluted areas (combined by weighting of the averages according to the number of children in each area) had declined, so that the annual means were respectively 48 and $140 \mu \mathrm{g} / \mathrm{m}^{3}$ for smoke, and 94 and $180 \mu \mathrm{g} / \mathrm{m}^{3}$ for $\mathrm{SO}_{2}$. The higher levels of smoke were almost three times the maximum levels of $50.5 \mu \mathrm{g} / \mathrm{m}^{3}$ measured in the national study during 1975 .

In other studies in the United Kingdom no relation has been observed between respiratory illness and winter mean levels of pollution above or within the range of levels studied here. In one study of families in a suburb of London no difference in the prevalence of illness was found between two areas in which the average winter mean levels of smoke from 1962 to 1965 were 94 and $130 \mu \mathrm{g} / \mathrm{m}^{3}$ while the winter mean of $\mathrm{SO}_{2}$ was similar in both areas at $247 \mu \mathrm{g} / \mathrm{m}^{3} .^{19}$ In another investigation of primary schoolchildren in $\mathrm{Kent}_{2}{ }^{20}{ }^{21}$ the difference in the prevalence of illness between three areas with average mean levels of smoke from December to February ranging from $\mathbf{4 0}$ to $79 \mu \mathrm{g} / \mathrm{m}^{3}$ was not consistent with an association with smoke.

The results of this study also conflict with findings from abroad ${ }^{22-24}$ and with the air quality standards of the World Health Organisation. ${ }^{12}$ In the WHO review it was felt that the effects of smoke on respiratory illness in the general population had not been found below an annual mean of $100 \mu \mathrm{g} / \mathrm{m}^{3}$ for both smoke and $\mathrm{SO}_{2}{ }^{12}$ It was recommended as a long-term goal that the annual means for both pollutants should not exceed 40 to $60 \mu \mathrm{g} / \mathrm{m}^{3}$. The maximum level of smoke studied here was within that range and although the annual mean for $\mathrm{SO}_{2}$ of $114 \cdot 1$ $\mu \mathrm{g} / \mathrm{m}^{3}$ in 1975 exceeded the range the levels of $\mathrm{SO}_{2}$ appeared to be unrelated to health.

In conclusion, the evidence from the epidemiological literature suggests that the association found between respiratory illness and levels of smoke in 1975 was unlikely to be caused by the levels measured during the year of investigation. As the levels of pollution had been declining in the United Kingdom before $1975^{1}$ past high levels of 
pollution may have caused the association. In at least two areas the annual means of both pollutants had been above $100 \mu \mathrm{g} / \mathrm{m}^{3}$ during the children's lifetime (the maximum annual means for both pollutants were approximately $200 \mu \mathrm{g} / \mathrm{m}^{3}$ in one area and 150 $\mu \mathrm{g} / \mathrm{m}^{3}$ in another). Alternatively, some other characteristic of the polluted areas in northern England may explain the association. To investigate whether changes in the levels of pollution during the study were associated with changes in health longitudinal analyses were conducted. The results are presented in the companion paper. ${ }^{4}$

The study was supported by a grant from the Department of Health and Social Security. We thank Professor W. W. Holland, Dr. Leslie Irwig, Mr. Douglas Altman, and Ms Lol Ide. We also thank the staffs of the area health authorities, the children's schools, and environmental and public health departments. Members of Warren Spring Laboratory, Stevenage, assisted in the siting of the pollution monitoring stations, processed the data on smoke and $\mathrm{SO}_{2}$, and helped us to maintain the quality of the data throughout the study.

Reprints from Dr. R. J. W. Melia, Department of Community Medicine, St. Thomas's Hospital Medical School, London SE1 7EH.

\section{References}

'Weatherley M-L PM, Gooriah BD, Charnock J. Fuel consumption, smoke and sulphur dioxide. Emissions and concentrations, and grit and dust deposition in the UK, up to 1973-4. LR $214(A P)$. Stevenage: Warren Spring Laboratory, 1976.

${ }^{2}$ Lunn JE, Knowelden J, Handyside AJ. Patterns of respiratory illness in Sheffield infant schoolchildren. $\mathrm{Br}$ J Prev Soc Med 1967; 21: 7-16.

${ }^{3}$ Lunn JE, Knowelden J, Roe JW. Patterns of respiratory illness in Sheffield Junior Schoolchildren. Br J Prev Soc Med 1970; 24: 223-8.

${ }^{4}$ Melia RJW, Florey C du V, Chinn S. Respiratory illness in British schoolchildren and atmospheric smoke and sulphur dioxide 1973-7, II Longitudinal findings. $J$ Epidemiol Community Health 1981; 35: 168-73.

${ }^{5}$ Altman DG, Cook J. A nutritional surveillance survey. Proc $R$ Soc Med 1973; 66: 646-7.

${ }^{6}$ Registrar General. Classification of Occupations, 1970. London: HMSO, 1977.

${ }^{7}$ Warren Spring Laboratory. National Survey of Smoke and Sulphur Dioxide Instruction Manual. Stevenage: Warren Spring Laboratory, 1966.
${ }^{8}$ Clifton M, Kerridge D, Moulds W, Pemberton J, Donoghue JK. The reliability of air pollution measurements in relation to the siting of instruments. Int $J$ Air Poll 1959; 2: 188-96.

${ }^{9}$ Melia RJW, Florey C du V, Altman DG, Swan AV. Association between gas cooking and respiratory disease in children. $\mathrm{Br}$ Med $J$ 1977; ii: 149-52.

${ }^{10}$ Melia RJW, Florey C du V, Chinn S. The relation between respiratory illness in primary schoolchildren and the use of gas for cooking. I-Results from a National Study. Int J Epidemiol 1979; 8: 333-8.

${ }^{11}$ Biersteker K. Sulfur Dioxide and Suspended Particulate Matter. Where do we stand? Environ Res 1976; 11: 287-304.

${ }^{12}$ World Health Organisation. Environmental Health Criteria 8. Sulfur Oxides and Suspended Particulate Matter. Geneva: World Health Organisation, 1979.

${ }^{13}$ Dyke SV, Patterson HD. Analysis of factorial arrangements when the data are proportions. Biometrics 1952; 8: 1-12.

${ }^{14}$ Rothamsted Experimental Station. Genstat. A general statistical program, 4.01. Harpenden, England: The Statistical Department, Rothamsted Experimental Station, 1977.

${ }^{15}$ Irwig L, Altman DG, Gibson RJW, Florey C du V. Air pollution: Methods to study its relationship to respiratory disease in British Schoolchildren. In: Recent Advances in the Assessment of the Health Effects of Environmental Pollution. Symposium Proceedings, vol. 1. Luxembourg: Commission of European Communities, 1975: 289-300.

${ }^{16}$ Melia RJW, Florey C du V, Swan AV. The effect of atmospheric smoke and sulphur dioxide on respiratory illness among British schoolchildren: a preliminary report. Paper given at the VIIIth International Scientific Meeting of the International Epidemiological Association, Puerto Rico, 1977.

${ }^{17}$ Bland JM, Holland WW, Elliott A. The development of respiratory symptoms in a cohort of Kent schoolchildren. Bull Physiopathol Respir 1974; 10: 699-716.

${ }^{18}$ Leeder SR, Corkhill R, Irwig LM, Holland WW, Colley JRT. Influence of family factors on the incidence of lower respiratory illness during the first year of life. $B r J$ Prev Soc Med 1976; 30: 203-12.

${ }^{19}$ Holland WW, Kasap HS, Colley JRT, Cormack W. Respiratory symptoms and ventilatory function: a family study. Br J Prev Soc Med 1969; 23: 77-84.

${ }^{20}$ Holland WW, Halil T, Bennett AE, Elliott A. Factors influencing the onset of chronic respiratory disease. $\mathrm{Br}$ Med J 1969; ii: 205-8.

${ }^{21}$ Holland WW, Halil T, Bennett AE, Elliott A. Indications of measures to be taken in childhood to prevent chronic respiratory disease. Milbank Mem Fund $Q$ 1969; 47: 215-27.

${ }^{22}$ Leeder SR, Woolcock AJ, Peat JK, Blackburn CRB. Relationship of air pollution to prevalence of lower respiratory illness and lung function in Australian schoolchildren. In: Recent Advances in the Assessment of the Health Effects of Environmental Pollution. Symposium Proceedings, vol. 1. Luxembourg: Commission of European Communities, 1975: 63-76.

${ }^{23}$ Liard R, Bourdeix J, Gally N, Perdrizet S. Symtômes respiratoires chez les enfants d'âge scolaire, dans deux quartiers de Lyon. Lyon Med 1979; 241: 269-72.

${ }^{24}$ World Health Organisation. The long-term effects on health of air pollution. Report of a Working Group, Rabka, 9-11 February, 1977, Copenhagen, Regional Office for Europe. Geneva: WHO, 1978. 